\title{
Managing Alzheimer Dementia Tomorrow
}

\author{
Thomas C. Rosenthal, MD, and Natan Khotianov, MD
}

Background: Acetylcholinesterase inhibitors are the first drugs to alter the devastating effects of Alzheimer disease. The next generation of drugs will prevent the $\beta$-amyloid plaques and neurofibrillary tangles or block enzymes that lead to neuron destruction. Effective use of these medications will require early identification of patients at risk.

Methods: Using the PubMed service of the National Library of Medicine, all English language articles published in 2000, 2001 and the first half of 2002 with a key word of 'dementia' were reviewed for articles that described the emerging pathophysiologic model for Alzheimer disease.

Findings: Standardized clinical screening tools, such as the mini-mental status examination and the clock test, administered longitudinally and correlated with family observations, can identify many atrisk patients. Genetic testing can identify a known mutation in $70 \%$ of patients who have a high family incidence of Alzheimer disease but awaits effective prevention before being useful. The molecular mechanisms of Alzheimer disease will eventually lead to prevention.

Conclusion: Today, these patients benefit from nutritional support and lifestyle enhancement encouraged through a continuous primary care relationship. (J Am Board Fam Pract 2003;16:423-34.)

Alzheimer disease is associated with an excessive number of extracellular $\beta$-amyloid plaques and intracellular neurofibrillary tangles in the cerebral cortex and subcortical gray matter. These plaques and tangles cause structural brain damage and extinguish cognitive functions in more than 3 million Americans and affect $16 \%$ of those older than 85 years. ${ }^{1-4}$ One in 10 elderly Americans has mild cognitive impairment and is at risk for Alzheimer disease. $^{5}$ Today, acetylcholinesterase inhibitors temporarily delay decline for some patients, but effective interruption of progression remains elusive. Biomolecular advances over the last 2 years have uncovered the events that lead to the production of plaques and tangles, revealing opportunities for intervention. Future pharmaceuticals will depend on understanding the pathogenic and molecular cascade leading to Alzheimer disease.

We will review the emerging molecular theories, genetics, early diagnostic techniques, and promising interventions of Alzheimer disease and correlate the new science to primary care. The goal is to facilitate the family physician when addressing questions posed by patients and families seeking

Submitted, revised, 13 December 2002.

From the Department of Family Medicine, State University of New York at Buffalo. Address reprint requests to Thomas C. Rosenthal, MD, 462 Grider Street, Buffalo, NY 14215 (e-mail: trosenth@acsu.buffalo.edu). solace for the alarming diagnosis of Alzheimer disease.

\section{Methods}

Using the PubMed service of the National Library of Medicine, all English language articles published in 2000, 2001, and the first half of 2002 with a key word of 'dementia' were identified. Articles describing advances in the understanding of the molecular basis, treatment, screening, and genetics of Alzheimer disease were further reviewed. Those findings that were confirmed in more than 1 research publication by different researchers or referenced in 2 review articles appearing in peerreviewed journals were selected for further analysis to construct a "prevailing" theory of the molecular pathogenesis of Alzheimer disease. The most recent or the most descriptive article has been referenced. Salient literature published before 2000 was accessed if referenced by current literature, in an attempt to focus on the theorems that remained current. The level of evidence for clinical recommendations were judged by the authors as follows: level A is supported by randomized clinical trial or meta-analysis, level B by other evidence, and level $\mathrm{C}$ by consensus or expert opinion.

\section{Results}

\section{The Emerging Molecular Theory}

Four major processes contribute to the brain destruction presenting clinically as Alzheimer disease. 
They are amyloid production, tangles formation, inflammation, and neurodegeneration or cell death. ${ }^{6}$ Each process contributes to and interrelates with the others in a maze of cause and effect that is still being elucidated.

\section{Amyloid}

Two decades of research have confirmed the significance of plaques formed from $\beta$-amyloid deposits in the extracellular spaces of the brain. These destructive plaques act like barnacles attaching to neurons. They are formed from a injurious mix of $\beta$-amyloid, inflammatory cells, and free radicals. ${ }^{7}$ The brains of aged, cognitively normal humans often contain a diffuse pattern of amyloid deposits, but few plaques. In Alzheimer disease, the plaques accumulate in the critical parietal, temporal cortex, and hippocampus areas associated with memory and learning functions. Much like fatty streaks organize into atherosclerotic plaques that damage arterial walls, amyloid deposits in some patients can organize into $\beta$-amyloid plaques that damage the cell walls of neurons. ${ }^{8}$

$\beta$-Amyloid is generated from large structural molecules called amyloid precursor proteins. ${ }^{9}$ Amyloid precursor proteins are transmembrane glycoproteins that play a role in cellular adhesion and membrane integrity. They are found in intracellular vesicles, such as the endoplasmic reticulum, Golgi apparatus, endosomes, and neurotransmitter secretory tubules, as well as the cell wall. Enzymes (secretases) on membrane surfaces cleave amyloid precursor proteins to form amyloid and other protein fragments that promote membrane function and also signal DNA transcription activity in the nucleus. Amyloid is present in the cerebrospinal fluid of healthy humans (and mice), but greater quantities are found in patients with Alzheimer disease.

Some secretases on membrane surfaces, using a 2-step process, cleave these amyloid precursor protein fragments into the insoluble $\beta$-amyloid. ${ }^{8}$ $\beta$-Amyloid formed in the cytoplasm of the cell is taken up by vesicles that fuse with the cell membrane and release into the extracellular space. Here, in Alzheimer disease, they aggregate into plaques.

$\beta$-Amyloid plaques activate astrocytes and glial cells, releasing cytokines, and acute phase reactants, and they trigger an inflammatory cascade. Binding of complement triggers altered ionic homeostasis, excessive calcium entry into neurons, hyperphosphorylation of $\tau$-protein, neuronal dysfunction, loss of synapses, pruning of dendrites, decreased neurotransmitter release (especially acetylcholine), and cell death. All the downstream effects of $\beta$-amyloid plaque accumulation have been difficult to place into their proper temporal sequence. ${ }^{8}$ However, the load and distribution of plaques formed from $\beta$-amyloid correlate directly with the severity and manifestation of Alzheimer disease.

\section{Neurofibrillary Tangles}

Neurofibrillary tangles are also pathognomonic for Alzheimer disease. They occur in large numbers within the cytoplasm of neurons, particularly in the frontal, temporal, and parietal cortex, hippocampus, and the amygdala. ${ }^{8}$ Tangles are paired helical filaments made of the remnants of damaged intracellular microtubules and hyperphosphorylated $\tau$-protein. $\tau$-Protein is a multifunctional protein that plays a role in the assembly and stabilization of microtubules. When $\tau$-protein is hyperphosphorylated, the tubules twist into compact filamentous structures and act like foreign bodies within the cell (Figure 1). Two enzymes, both kinases ( $\mathrm{Cdk} 5$ and Csk-3 $\beta$ ) are overly active in Alzheimer disease, with $\beta$-amyloid playing a role in their activation. ${ }^{10}$

\section{Protease Enzymes and Amyloid}

The enzymes that fragment the amyloid precursor proteins are called secretases. Precursor proteins are split in sequence. The first sequence can be at 1 of 2 sites, by 2 different secretases ( $\alpha$ - or $\beta$-secretase). Both secretases are found in most membranes, including the Golgi apparatus, endosomes, and the plasma membrane. Only $\beta$-secretase, also called BACE, creates the substrate from which $\beta$-amyloid can be produced. It is unclear whether both secretases are essential, because mice bred to be devoid of $\beta$-secretase seem normal except that they do not accumulate $\beta$-amyloid. ${ }^{11}$

As shown in Figure 2, there is a further cleavage necessary to produce $\beta$-amyloid. $\gamma$-Secretase further splits the fragments of amyloid precursor protein produced by $\beta$ - and $\alpha$-secretase. When the fragments created by $\beta$-secretase are acted on by $\gamma$-secretase, the insoluble $\beta$-amyloid, a 42 -amino acid fragment, is produced. Presenilins are cofactors of $\gamma$-secretase or, as recent evidence suggests, they actually are $\gamma$-secretase. Altered production of 


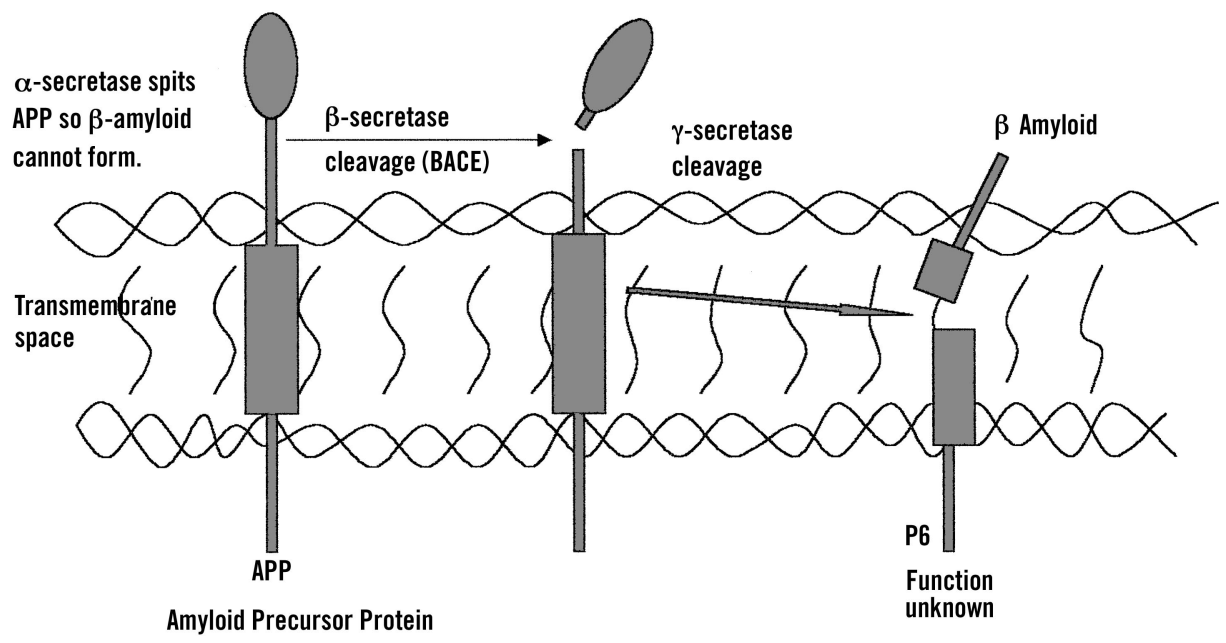

Figure 1. Secretase and Alzheimer disease. Amyloid precursor proteins (APP) serve active and passive structural functions in the cell wall of neurons. To be activated, they are cleaved by $\alpha$-secretase fragments that may play a role in cell adhesion. $\beta$-Secretase cleaves APP at a different site, producing a 42 -amino acid fragment that can further be acted on by $\gamma$-secretase to produce $\beta$-amyloid, a protein fragment with low solubility that can aggregate and adhere to the neuron cell wall causing damage.

presenilins, as seen in some at-risk families, results in an increase of $\beta$-amyloid. ${ }^{11}$

Pharmaceutical researchers are actively pursuing drugs to block $\beta$ - or $\gamma$-secretase or enhance $\alpha$-secretase. ${ }^{9}$ There are also several cofactors necessary to activate secretase that may be manipulated to decrease the formation of $\beta$-amyloid. These include the cell surface immunoglobulin molecule receptor for glycation end products (RAGE) and $\beta$ amyloid binding alcohol dehydrogenase (ABAD). ${ }^{12}$
Inhibiting the phosphorylation of $\tau$-protein by kinase enzymes is another potential target for prevention. The kinase Cdk5 plays a critical role in brain development, neurogenesis, dopamine signaling, and synaptic vesicle release, but selective inhibitors of Cdk 5 and GSK $3 \beta$, such as lithium, have demonstrated limited protection against neuronal death in cell culture. ${ }^{10}$ However, because of its essential role in brain development, enthusiasm for kinase inhibition has been restrained. It is also

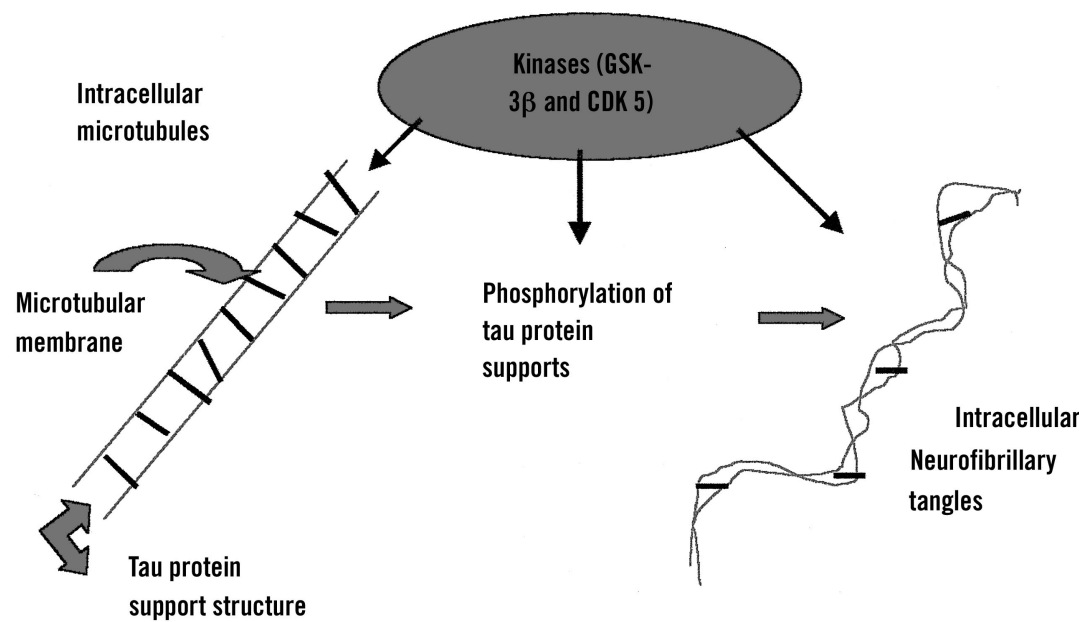

Figure 2. $\tau$-Protein phosphorylation. The role of $\tau$-protein in the cell is to provide structural support to microtubules. In the presence of kinase, $\tau$ can become phosphorylated, causing microtubules to disorganize and form tangles that disrupt intracellular transport. Phosphorylation seems to be influenced by the presence of $\beta$ amyloid. 
generally accepted that $\tau$ phosphorylation is a downstream event to $\beta$-amyloid production. ${ }^{6}$

\section{Microischemia and Amyloid}

Dementia, including Alzheimer disease, is more likely to develop in persons with cerebrovascular disease. ${ }^{13,14}$ Ischemia in the microcirculation of the temporal lobes of patients with Alzheimer disease results in low oxygen tension and $\beta$-amyloid production, much as ischemia causes amyloid deposits in the heart. ${ }^{15}$ Supporters of ischemia theories of Alzheimer disease postulate that amyloid precursor protein production increases to protect the cell membranes from the oxidative stress of ischemia. ${ }^{16}$ More amyloid precursor protein begets more $\beta$-amyloid, causing the clinical abnormalities seen in Alzheimer disease. ${ }^{16}$

\section{Apolipoprotein and Amyloid}

Apolipoprotein E plays a role in the transport of cholesterol and phospholipids. It is encoded by a gene on the long arm of chromosome 19. There are 3 isoforms, each of which codes for a slight variation in the amino acid sequence. The E4 allele increases the susceptibility to Alzheimer disease through increased disposition of amyloid plaques and decreased clearance of $\beta$-amyloid. In the brain, apolipoproteins are essential for cytoskeletal integrity and neuronal repair mechanisms, making them unfavorable targets for manipulations to alter $\mathrm{Alz}$ heimer disease. ${ }^{17,18}$

Homocysteine is associated with cardiovascular disease and stroke and is emerging as a risk factor for Alzheimer disease. It promotes amyloidpeptide-mediated toxic effects in neuronal cell cultures and induces apoptosis in rat neurons. In a prospective study of 1000 nondemented Framingham residents over the age of 76 years, not only were homocysteine levels predictive of Alzheimer dementia but also the higher the level, the greater the risk. ${ }^{19}$ The impact of homocysteine was not altered by educational levels, systolic blood pressure, smoking, alcohol intake, diabetes, obesity, stroke, or the apolipoprotein E genotype. ${ }^{19}$

\section{Amyloid and Neurotransmitters}

Degeneration of the neurons and loss of dendrites profoundly reduces the production of acetylcholine. A loss of $60 \%$ to $90 \%$ of acetylcholine activity results in memory impairment. Other neurotrans- mitters depleted in Alzheimer disease include serotonin by $50 \%$ to $70 \%$, somatostatin by $40 \%$ to $60 \%$ and norepinehrine by $30 \%$ to $70 \%$. Receptors for serotonin, glutamate, somatostatin, and acetylcholine are reduced also. ${ }^{20}$ Symptomatic treatment of Alzheimer disease has focused on augmenting neurotransmission by increasing the brain's cholinergic supply. Greatest success has been obtained by blocking the enzyme acetylcholinesterase, which clears acetylcholine from the synapse. Tacrine, donepezil, rivastigmine, and galanthamine, all of which are acetylcholinesterase inhibitors, have confirmed efficacy (level A) in temporarily delaying the progression of Alzheimer dementia. ${ }^{21}$

\section{Inflammation}

All pathologic studies in Alzheimer disease confirm the accumulation of microglia around $\beta$-amyloid plaques. ${ }^{22}$ Microglial cells clean up debris and cellular damage in the brain but in the process release free radicals and cytokines that activate astrocytes. Astrocytes, the largest cell population in the brain, provide metabolic support to neurons but add to the oxidative imbalance. Consequently, an inflammatory cascade is initiated. ${ }^{10}$

Numerous anti-inflammatory approaches have been studied. Prednisone has not been effective in Alzheimer disease, and celecoxib, the selective cyclo-oxygenase inhibitor, has not been shown to arrest disease progression but is epidemiologically associated, as are other nonsteroidal anti-inflammatory drugs (NSAIDs), with a protective effect. ${ }^{6}$

\section{Genetics}

Only $10 \%$ to $20 \%$ of cases suggest a familial mode of transmission, but understanding phenotypes produced by these mutations has contributed a great deal to the understanding of Alzheimer disease. Mutations in 4 genes have been affirmed to increase risk for Alzheimer disease, but other mutations are in various stages of study. ${ }^{23}$ First, the amyloid precursor protein gene, found on chromosome 21, results in increased production of precursor proteins and may explain the prevalence of Alzheimer disease in Down syndrome. ${ }^{11}$

Second, the Presenilin 1 gene, located on chromosome 14 , increases the activity of secretase and accounts for $4 \%$ of early-onset Alzheimer disease cases between the ages of 28 and 50 years. The third mutation, Presenilin 2, on chromosome 1, 
accounts for $1 \%$ of Alzheimer disease cases with onset between 40 and 50 years of age. ${ }^{24}$ The presenilin mutations increase levels of $\gamma$-secretase (and in fact may be $\gamma$-secretase) and result in an aggressive form of inherited Alzheimer disease. ${ }^{25}$

The fourth and most common form of inherited Alzheimer disease is associated with one of several mutations on chromosome 19, the apolipoprotein $\mathrm{E}$ alleles. These mutations cause enhanced aggregation and decreased clearance of amyloid peptides in the brain. Their expression is variable, but they account for $50 \%$ of early Alzheimer disease and $20 \%$ of late-onset disease. The presence of the $\epsilon 4$ allele mutation increases the risk for Alzheimer disease in whites and $\epsilon 2$ and 4 alleles increase the risk in African Americans. Apolipoprotein genotyping is commercially available but offers little advantage as a prognostic indicator. Female carriers have a $45 \%$ probability of developing Alzheimer disease by age 73 and male carriers have only a $25 \%$ probability. Genetic testing is useful only with atypical presentations of Alzheimer disease. ${ }^{2,27}$ The heterogeneity in late-onset, sporadic Alzheimer disease complicates interpretation of genetic profiling. ${ }^{28}$

Currently, a DNA diagnosis is possible in $70 \%$ of families with a pattern of autosomal-dominant Alzheimer disease. For first-degree relatives of carriers, lifetime risk (onset by age 90) is increased some 3 - or 4 -fold relative to control subjects. ${ }^{29}$ Patient response to genetic testing is not well studied, but with proper counseling, most patients demonstrate effective coping skills and find testing constructive. ${ }^{30}$ Testing concerns include expense, accuracy, limited understanding of risk calculations, insurance denials, emotional impact, and deterministic behavior leading to unnecessary risk exposure. There is very little clinical evidence to support genetic testing for a known Alzheimer disease mutation and no evidence to support the use of genetic testing as a screening tool.

\section{Early Diagnosis}

Identifying patients at risk for Alzheimer disease, and developing strategies that modify the disease are the most urgent challenges facing researchers. Disease modification is likely to be of greatest benefit if begun early. Defining clinical patterns and searching for molecular markers of preclinical Alzheimer disease are active areas of research.

\section{Clinical Identification of Early or pre-Alzbeimer Disease}

Clinical risk factors for Alzheimer disease include advanced age, malnutrition, small head size, head trauma, and female sex. Decreased sensory responsiveness caused by declines in vision and hearing can lead to decreased awareness, and depression, putting the patient at risk for dementia. Selfreported poor general health is associated with a 5 -fold increase in the development of Alzheimer dementia. ${ }^{31}$ Many elderly patients have mild cognitive impairment but use compensatory strategies in everyday living. Only 20\% of these patients will progress to dementia. ${ }^{32}$

Motor skills decline can also be predictive. Subjects who later develop cognitive impairment have slower finger tapping, take longer to walk 30 feet, and have an inability to suppress the eye-blink response to sudden movement. ${ }^{33-35}$

Framingham Study participants have confirmed difficulty with verbal memory, a temporal lobe activity, as an early sign of Alzheimer disease. ${ }^{36-39}$ Families perceive verbal memory problems as forgotten telephone arrangements but compensate by suggesting the date be written down. On the MiniMental Status Examination, recalling 3 objects is verbal memory-sensitive. ${ }^{40}$

\section{Clock Test}

The search for a standardized scoring system capable of reliably predicting dementia remains elusive. ${ }^{41,42}$ The clock-drawing test is a simple measure of visuospatial ability; there is relatively little overlap between patients with Alzheimer disease and healthy control subjects early in the disease (Figure 3). ${ }^{43}$ It is quick and easy to administer. Recent studies suggest the clock test provides $85 \%$ sensitivity and $85 \%$ specificity and correlates well with other cognitive tests (level B). ${ }^{44}$

Unfortunately, the use of cognitive scales in an unselected elderly population produces many false positives because of significant cultural, mood, or education variation. ${ }^{45-47}$ Standardized scales are most useful for evaluation of patient or family concerns about cognitive decline. If the clinician cannot substantiate a deficit during clinical testing, progressive deterioration is much less likely. ${ }^{48}$

There is level B evidence to recommend that a patient who is identified to be at risk for Alzheimer disease should undergo cognitive measurement by a standardized scoring system such as the clock test 


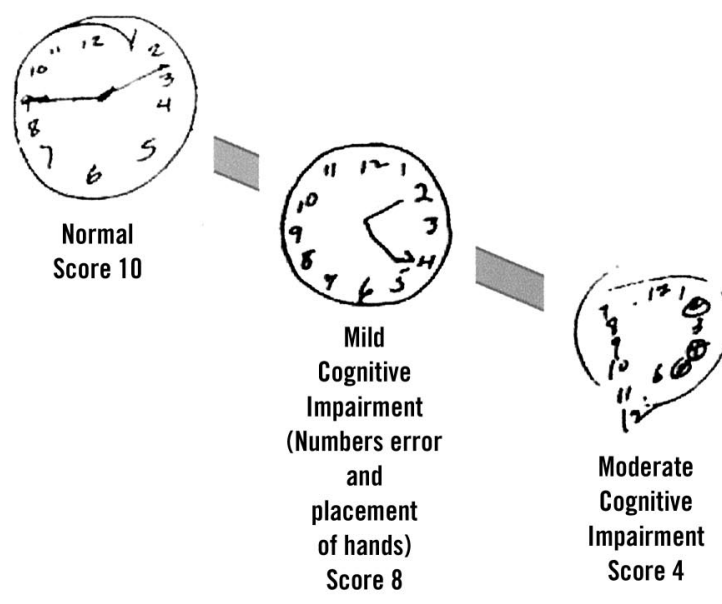

Sunderland, 1989

UB

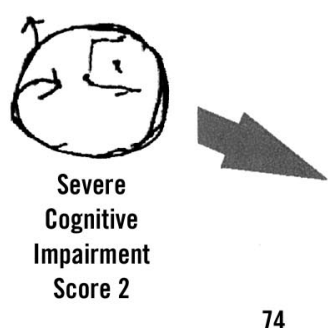

74

Figure 3. Clock drawing test. The patient is asked to draw clock displaying the time 2:45. This simple test has been shown to be more sensitive of early Alzheimer dementia than several other screening tools and can be scored according to standard protocols. ${ }^{43}$

or the Folstein Mini-Mental Status Examination. This scoring should be repeated every 6 to 12 months thereafter. If there is a decline of 3 points, the patient should be considered at risk for the onset of dementia and evaluated for treatment. ${ }^{49}$

\section{Laboratory Identification of pre-Alzheimer Disease}

The goal of a laboratory work-up in a patient with suspected Alzheimer disease is to assure an accurate diagnosis of the disorder responsible for the dementia and discover correctable conditions. The treatment plan is altered in up to $13 \%$ of patients after a laboratory work-up. ${ }^{50,51}$ Patients should have a complete blood count, electrolyte panel, a comprehensive metabolic panel, thyroid function tests, syphilis serology, vitamin $B_{12}$ and folate levels, and pre-albumen (level B). ${ }^{52,53}$ Determination of erythrocyte sedimentation rate, HIV antibody screen, toxicology screen, and chest radiograph should be ordered if indicated by history or physical examination. ${ }^{52}$

Advertisements for a urine screen capable of diagnosing Alzheimer disease have appeared in the lay press. This screen tests for breakdown products of arachidonic acid that appear in the urine of patients with Alzheimer dementia. ${ }^{54}$ Overlap between healthy elderly patients and those with Alzheimer dementia renders this test too nonspecific for clinical recommendation.
Several substances in blood and cerebrospinal fluid are under study as diagnostic markers for Alzheimer disease. ${ }^{6}$ Autoantibodies to $\beta$-amyloid and neurotransmitters have been demonstrated in the blood of patients with Alzheimer disease. ${ }^{55,56}$ Melanotransferrin (p97) originates from the microglia activated by the $\beta$-amyloid plaques and can be detected in the cerebrospinal fluid. ${ }^{57}$ There are elevated levels of $\beta$-amyloid and $\tau$-protein in cerebrospinal fluid and high levels of $\beta$-amyloid in plasma. None of these markers are yet available for clinical use. ${ }^{58,59}$

\section{Imaging in pre-Alzheimer Disease}

Most patients should undergo computed tomography (CT) or magnetic resonance imaging (MRI) of the head. ${ }^{52,60}$ Not only are other conditions ruled out by imaging but also decreased hippocampal volume precedes Alzheimer disease in $50 \%$ to $70 \%$ of patients. ${ }^{61}$ The association between brain volume and function remains significant after adjusting for age and has been confirmed in African Americans and white persons. ${ }^{62-66}$ Positron emission tomography (PET) to detect accumulation of $\beta$-amyloid plaques in memory-related brain regions correlate with disability and are $93 \%$ sensitive and $76 \%$ specific. $^{67,68}$

As we have shown, routine screening with available tools is not cost-effective. ${ }^{69}$ Clinical suspicion 
Table 1. Strategies to Slow the Onset or Progression of Dementia

\begin{tabular}{|c|c|c|}
\hline Strategy & Comments & Evidence \\
\hline Maintain general health & Diet, exercise, cardiovascular risk factors & Level B \\
\hline Intellectual achievement & $\begin{array}{l}\text { Challenging work. } \\
\text { Memory games have been shown to } \\
\text { increase dendrites. }\end{array}$ & Level B \\
\hline Acetylcholinesterase inhibitors & $\begin{array}{l}\text { Induce limited improvement in } \\
\text { responders that can last } 1 \text { or more } \\
\text { years. }\end{array}$ & Level A \\
\hline$\beta$-Secretase inhibition & $\begin{array}{l}\text { Critical enzyme in the production of } \\
\beta \text {-amyloid. } \\
\text { Inhibitors capable of crossing the blood- } \\
\text { brain barrier are under development. }\end{array}$ & Basic research \\
\hline Immunotherapy & $\begin{array}{l}\text { Antibodies to } \beta \text {-amyloid increase its } \\
\text { clearance from the brain in mice. }\end{array}$ & Basic research in humans has begun. \\
\hline Vitamin E (antioxidant) & $\begin{array}{l}\text { Has been demonstrated to slow } \\
\text { Alzheimer disease progression in } \\
\text { humans but did not improve function. }\end{array}$ & Level A \\
\hline $\begin{array}{l}\text { Other antioxidants (ginkgo biloba, } \\
\text { vitamin } \mathrm{C} \text {, selegiline) }\end{array}$ & $\begin{array}{l}\text { Results are inconsistent, ranging from no } \\
\text { benefit to minimal delayed } \\
\text { progression. }\end{array}$ & Inconsistent, probably not effective. \\
\hline Estrogen & $\begin{array}{l}\text { Alters cholinergic, serotonergic, and } \\
\text { catecholaminergic neurotransmitter } \\
\text { systems but increases incidence of } \\
\text { ASHD. }\end{array}$ & $\begin{array}{l}\text { Inconsistent, possibly limited by side } \\
\text { effects. }\end{array}$ \\
\hline $\begin{array}{l}\text { Nonsteroidal anti-inflammatory drugs } \\
\text { (NSAIDs) }\end{array}$ & $\begin{array}{l}\text { Effective only if started in the preclinical } \\
\text { phase and used for a minimum of } 2 \\
\text { years }\end{array}$ & $\begin{array}{l}\text { Level B but limited by side effects. Some } \\
\text { inconsistency in clinical trials, } \\
\text { especially with cyclooxygenase } 2 \\
\text { inhibitors. }\end{array}$ \\
\hline $\begin{array}{l}\text { 3-Hydroxy-3-methylglutaryl-coenzyme A } \\
\text { (HMG-CoA) reductase inhibitors } \\
\text { (statins) }\end{array}$ & $\begin{array}{l}\text { There is observational evidence that } \\
\text { aggressive treatment of hypertension } \\
\text { and hyperlipidemia retards onset of } \\
\text { Alzheimer disease. }\end{array}$ & Level B \\
\hline
\end{tabular}

aroused during continuity care confirmed by focused clinical and laboratory testing remains the best way to identify patients at risk for Alzheimer disease. $^{70}$

\section{Altering the Course of Alzheimer Disease}

Maintaining the general health status of elderly patients is the most effective strategy to lessen the impact of Alzheimer disease on a population. Table 1 lists strategies that have been proposed along with available evidence. Modifying cardiovascular risk factors, such as hypertension and high cholesterol, and homocysteine levels impact both heart disease and dementia (level B). ${ }^{19,71}$ Continued intellectual and occupational achievement, even memory games, increase dendrites and delay clinical manifestations. ${ }^{72}$ Good nutrition enhances functional speed and brain efficiency. ${ }^{72}$

Cholinesterase inhibitors induce modest improvement in cognitive function for a limited span of time. ${ }^{73}$ Although indicated in mild to moderate disease, they are not neuroprotective and offer little clinical improvement when the Mini-Mental Status Examination score drops below $12 .^{74}$ In the near future, neuroprotective approaches will focus on amyloid precursor protein, amyloid metabolism, and general neurodegenerative processes such as inflammation and oxidation. ${ }^{75}$

\section{Decreasing $\beta$-Amyloid Accumulation}

All humans experience a continuum of $\beta$-amyloid production and clearance, but in Alzheimer disease, plaques damage dendrites, stimulate the inflammatory response, and kill neurons. Tangle formation, universal to Alzheimer disease, is probably secondary to $\beta$-amyloid production. It is likely that in the next few years, drugs capable of inhibiting $\beta$ - and $\gamma$-secretase will emerge.

The neuron membrane-bound enzyme $\beta$-secretase is a prime target for drug development because of its critical instigating role in the formation of $\beta$-amyloid (Figure 2). It was identified in 1999 and appears in the literature under several names (ie, BACE1, Asp2, memapsin2). Mice that lack 
$\beta$-secretase do not produce brain $\beta$-amyloid but develop normally, increasing the optimism that suppressing $\beta$-secretase activity has potential. Several nonpeptide, small-molecule inhibitors of $\beta$-secretase capable of crossing the blood-brain barrier are under development. ${ }^{6,75}$

Genetic mutations (PS1, PS2) result in altered structure of $\gamma$-secretase and result in early-onset Alzheimer disease. $\gamma$-Secretase cleaves amyloid precursor proteins in cellular and subcellular membranes (Figure 2). However, $\gamma$-secretase "knockout" mice die in utero, raising caution among researchers. Still, several modulators of $\gamma$-secretase activity, such as nicastrin, selectively inhibit amyloid precursor breakdown and decrease $\beta$-amyloid production. ${ }^{6,75,76}$

\section{Immunotherapy}

Immunotherapy has been met with enthusiasm until recently. Antibodies to $\beta$-amyloid increase its clearance from the brain. In mice, prophylactic immunization, even by a nasal application of a $\beta$-amyloid fragment, reduces $\beta$-amyloid plaque and tangle formation and protects against learning and memory impairments. ${ }^{77-79}$ Unfortunately, a $\beta$-amyloid immunization trial in humans had to be discontinued because of a high incidence of encephalitis in treatment subjects. Human subjects selected for these preliminary studies already had Alzheimer disease with a significant load of $\beta$ amyloid before enrollment. It is possible that the antibody-antigen reaction induced resulted in the encephalitis-like event. More studies will follow.

\section{Inflammation}

Vitamin E ( $\alpha$-tocopherol), a lipid-soluble vitamin antioxidant, traps free radicals like those present in $\beta$-amyloid plaques. In animal studies, vitamin $\mathrm{E}$ reduced degeneration of hippocampal neurons; in humans, it has been demonstrated to slow Alzheimer disease progression, although it did not improve function. The dose ranges studied were between $400 \mathrm{IU}$ and 1000 IU twice per day (level A). ${ }^{80,81}$

Other antioxidants, such as ginkgo biloba, vitamin C, selegiline (an monoamine oxidase inhibitor with an antioxidant effect), and nicergoline have shown inconsistent results that range from no benefit to minimal delayed progression of Alzheimer disease. ${ }^{80,82,83}$
Estrogen has a weak antioxidant effect and has been shown to alter cholinergic, serotonergic, and catecholaminergic neurotransmitter systems. Men convert testosterone to estrogen in the brain and are less likely to experience late-life estrogen deficiency. Several short-term estrogen supplemental studies in women demonstrated improved mood and psychologic function over 6 to 12 weeks, but others failed to show any effect after 12 months. ${ }^{84,85}$ The Women's Health initiative, a prospective study, has identified a slightly increased risk of dementia in the estrogen/progestin group, but this may be due to increased atherosclerotic vascular disease. ${ }^{86}$ One published meta-analysis suggests there is possibly a cognitive benefit to estrogen but recommends the use of estrogen only in women with other indications for hormones supplemention. ${ }^{87}$ Another more recent longitudinal study demonstrated a clinically significant reduction in dementia for both men and women taking estrogen (inconsistent). ${ }^{88}$

NSAIDs have been associated with lower risk and slower rate of decline in Alzheimer disease but only if they are started in the preclinical phase and used for a minimum of 2 years (level B). ${ }^{22,89}$ The largest studies to date have been observational. The varying dosages used in these studies makes it difficult to confidently recommend a minimum effective dose, but a sub-anti-inflammatory dose seem to be protective for some agents. ${ }^{90}$ Acetaminophen and prednisone have no effect, and aspirin has less effect than NSAIDs. ${ }^{20}$ One 12 -month trial failed to show a protective effect of celecoxib. ${ }^{6}$

\section{Treating Cholesterol}

People with systolic hypertension, high low-density lipoprotein (LDL), or high apolipoprotein $\mathrm{E}$ in midlife have 3 times the risk of Alzheimer disease in later life. ${ }^{14,91}$ Epidemiologic studies have demonstrated that 3-hydroxy-3-methylglutaryl-coenzyme A (HMG-CoA) reductase inhibitors (statins) used to control hyperlipidemia are associated with a $60 \%$ lower incidence of Alzheimer disease. ${ }^{92,93}$ There is mounting evidence that lowering serum cholesterol retards the onset of Alzheimer disease. ${ }^{94}$ The role of folic acid in the reduction of homocysteine is also interesting.

For inflammation and hypercholesterolemia, the observations are mostly epidemiologic. Although ongoing intervention trials will further define treatment effect, there is ample evidence that aggressive 
treatment of hypertension and hyperlipidemia prevents atherosclerosis (level B). There is mounting evidence that antioxidants and anti-inflammatory agents can alter disease onset (level B). ${ }^{95}$ It is likely that success in management of chronic diseases will protect some patients from Alzheimer disease. ${ }^{81}$

\section{Conclusions}

Alzheimer-type dementia remains a clinical diagnosis. However, neuroimaging by CT or MRI with attention to the hippocampal region in the initial evaluation of patients with dementia is appropriate for confirmation and staging. Currently, no genetic markers can be recommended for routine diagnostic purposes; however, screening for depression, $\mathrm{B}_{12}$ deficiency, and hypothyroidism should be performed on most patients. ${ }^{52}$ Treatment should include multiple modalities, just as prevention of atherosclerosis does now. Active lifestyle and vitamin $\mathrm{E}$ can be recommended for most elderly patients. NSAIDs and estrogen may be recommended to patients with coexisting indications. Acetylcholinesterase inhibitors should be discussed as a palliative treatment when decline is detected on a standardized score. The family physician should be optimistic that effective preventative modalities will be released in the next several years. Effective use of newer agents will be dependent on the family physician's first-hand knowledge of the patient's baseline.

\section{References}

1. DeKosky ST, Orgogozo JM. Alzheimer disease: diagnosis, costs, and dimensions of treatment. Alzheimer Dis Assoc Disord 2001;15 Suppl 1:S3-7.

2. Hendrie HC, Ogunniyi A, Hall KS, et al. Incidence of dementia and Alzheimer disease in 2 communities: Yoruba residing in Ibadan, Nigeria, and African Americans residing in Indianapolis, Indiana. JAMA 2001;285:739-47.

3. Evans DA, Funkenstein HH, Albert MS, et al. Prevalence of Alzheimer's disease in a community population of older persons. Higher than previously reported. JAMA 1989;262:2551-6.

4. Sloane PD, Zimmerman S, Suchindran C, et al. The public health impact of Alzheimer's disease, 20002050: potential implication of treatment advances. Annu Rev Public Health 2002;23:213-31.

5. Unverzagt FW, Gao S, Baiyewu O, et al. Prevalence of cognitive impairment: data from the Indianapolis Study of Health and Aging. Neurology 2001;57: 1655-62.

6. Scorer CA. Preclinical and clinical challenges in the development of disease-modifying therapies for Alzheimer's disease. Drug Discov Today 2001;6: 1207-19.

7. Olson RE, Copeland RA, Seiffert D. Progress towards testing the amyloid hypothesis: inhibitors of APP processing. Curr Opin Drug Discov Devel 2001;4:390-401.

8. Selkoe DJ. The genetics and molecular pathology of Alzheimer's disease: roles of amyloid and the presenilins. Neurol Clin 2000;18:903-22.

9. Jhee S, Shiovitz T, Crawford AW, Cutler NR. Betaamyloid therapies in Alzheimer's disease. Expert Opin Investig Drugs 2001;10:593-605.

10. Maccioni RB, Munoz JP, Barbeito L. The molecular bases of Alzheimer's disease and other neurodegenerative disorders. Arch Med Res 2001;32:367-81.

11. Esler WP, Wolfe MS. A portrait of Alzheimer secretases-new features and familiar faces. Science 2001;293:1449-54.

12. Yan SD, Roher A, Chaney M, Zlokovic B, Schmidt AM, Stern D. Cellular cofactors potentiating induction of stress and cytotoxicity by amyloid betapeptide. Biochim Biophys Acta 2000;1502:145-57.

13. Hensley K, Butterfield DA, Hall N, et al. Reactive oxygen species as causal agents in the neurotoxicity of the Alzheimer's disease-associated amyloid beta peptide. Ann NY Acad Sci 1996;786:120-34.

14. Kivipelto M, Helkala EL, Laakso MP, et al. Midlife vascular risk factors and Alzheimer's disease in later life: longitudinal, population based study. BMJ 2001; 322:1447-51.

15. Chorsky RL, Yaghmai F, Hill WD, Stopa EG. Alzheimer's disease: a review concerning immune response and microischemia. Med Hypotheses 2001; 56:124-7.

16. Blass JP. Brain metabolism and brain disease: is metabolic deficiency the proximate cause of Alzheimer dementia? J Neurosci Res 2001;66:851-6.

17. Kuusisto J, Koivisto K, Kervinen K, et al. Association of apolipoprotein $\mathrm{E}$ phenotypes with late onset Alzheimer's disease: population based study. BMJ 1994;309:636-8.

18. Saunders AM, Trowers MK, Shimkets RA, et al. The role of apolipoprotein $\mathrm{E}$ in Alzheimer's disease: pharmacogenomic target selection. Biochim Biophys Acta 2000;1502:85-94.

19. Seshadri S, Beiser A, Selhub J, et al. Plasma homocysteine as a risk factor for dementia and Alzheimer's disease. N Engl J Med 2002;346:476-83.

20. Cummings JL, Vinters HV, Cole GM, et al. Alzheimer's disease: etiologies, pathophysiology, cognitive reserve, and treatment opportunities. Neurology 1998;51(1 Suppl 1):S2-17; discussion S65-7.

21. Francis PT, Palmer AM, Snape M, Wilcock GK. The cholinergic hypothesis of Alzheimer's disease: a review of progress. J Neurol Neurosurg Psychiatry 1999;66:137-47.

22. in t' Veld BA, Ruitenberg A, Hofman A, et al. Non- 
steroidal antiinflammatory drugs and the risk of $\mathrm{Alz}$ heimer's disease. N Engl J Med 2001;345:1515-21.

23. Retz W, Thome J, Durany N, et al. Potential genetic markers of sporadic Alzheimer's dementia. Psychiatr Genet 2001;11:115-22.

24. Athan ES, Williamson J, Ciappa A, et al. A founder mutation in presenilin 1 causing early-onset Alzheimer disease in unrelated Caribbean Hispanic families. JAMA 2001;286:2257-63.

25. Selkoe DJ. Alzheimer's disease: genes, proteins, and therapy. Physiol Rev 2001;81:741-66.

26. Breitner JC, Wyse BW, Anthony JC, et al. APOEepsilon4 count predicts age when prevalence of $\mathrm{AD}$ increases, then declines: the Cache County Study [published erratum appears in Neurology 2000;55: 161-2.] Neurology 1999;53:321-31.

27. Tanzi RE, Bertram L. New frontiers in Alzheimer's disease genetics. Neuron 2001;32:181-4.

28. Brayne C, Harrington CR, Wischik CM, et al. Apolipoprotein $\mathrm{E}$ genotype in the prediction of cognitive decline and dementia in a prospectively studied elderly population. Dementia 1996;7:169-74.

29. Liddell MB, Lovestone S, Owen MJ. Genetic risk of Alzheimer's disease: advising relatives. Br J Psychiatry 2001;178:7-11.

30. Steinbart EJ, Smith CO, Poorkaj P, Bird TD. Impact of DNA testing for early-onset familial Alzheimer disease and frontotemporal dementia. Arch Neurol 2001;58:1828-31.

31. Weisen SF, Frishman WH, Aronson MK, Wassertheil-Smoller S. Self-rated health assessment and development of both cardiovascular and dementing illnesses in an ambulatory elderly population: a report from the Bronx Longitudinal Aging Study. Heart Dis 1999;1:201-5.

32. Wolf H, Grunwald M, Ecke GM, et al. The prognosis of mild cognitive impairment in the elderly. J Neural Transm Suppl 1998;54:31-50.

33. Camicioli R, Howieson D, Oken B, Sexton G, Kaye J. Motor slowing precedes cognitive impairment in the oldest old. Neurology 1998;50:1496-8.

34. Andel R, Gatz M, Pedersen NL, Reynolds CA, Johansson B, Berg S. Deficits in controlled processing may predict dementia: a twin study. J Gerontol B Psychol Sci Soc Sci 2001;56:P347-55.

35. Woodruff-Pak DS. Eyeblink classical conditioning differentiates normal aging from Alzheimer's disease. Integr Physiol Behav Sci 2001;36:87-108.

36. Linn RT, Wolf PA, Bachman DL, et al. The 'preclinical phase' of probable Alzheimer's disease. A 13 -year prospective study of the Framingham cohort. Arch Neurol 1995;52:485-90.

37. Howieson DB, Dame A, Camicioli R, Sexton G, Payami H, Kaye JA. Cognitive markers preceding Alzheimer's dementia in the healthy oldest old. J Am Geriatr Soc 1997;45:584-9.

38. Derrer DS, Howieson DB, Mueller EA, Camicioli RM, Sexton G, Kaye JA. Memory testing in demen- tia: how much is enough? J Geriatr Psychiatry Neurol 2001;14:1-6.

39. Halpern AR, O'Connor MG. Implicit memory for music in Alzheimer's disease. Neuropsychology 2000;14:391-7.

40. Teng EL, Chui HC. The Modified Mini-Mental State (3MS) examination. J Clin Psychiatry 1987;48: 314-8.

41. Argyriadou S, Vlachonikolis I, Melisopoulou H, Katachanakis K, Lionis C. In what extent anemia coexists with cognitive impairment in elderly: a cross-sectional study in Greece. BMC Fam Pract 2001;2:5.

42. Hogervorst E, Combrinck M, Lapuerta P, Rue J, Swales K, Budge M. The Hopkins Verbal Learning Test and screening for dementia. Dement Geriatr Cogn Disord 2002;13:13-20.

43. Sunderland T, Hill JL, Mellow AM, et al. Clock drawing in Alzheimer's disease. A novel measure of dementia severity. J Am Geriatr Soc 1989;37:725-9.

44. Shulman KI. Clock-drawing: is it the ideal cognitive screening test? Int J Geriatr Psychiatry 2000;15: 548-61.

45. Flicker L, Logiudice D, Carlin JB, Ames D. The predictive value of dementia screening instruments in clinical populations. Int J Geriatr Psychiatry 1997; 12:203-9.

46. O'Connor DW, Pollitt PA, Roth M, Brook PB, Reiss BB. Memory complaints and impairment in normal, depressed, and demented elderly persons identified in a community survey. Arch Gen Psychiatry $1990 ; 47: 224-7$.

47. O'Connor DW, Pollitt PA, Treasure FP, Brook CP, Reiss BB. The influence of education, social class and sex on Mini-Mental State scores. Psychol Med 1989; 19:771-6.

48. Flicker C, Ferris SH, Reisberg B. A longitudinal study of cognitive function in elderly persons with subjective memory complaints. J Am Geriatr Soc 1993;41:1029-32.

49. Petersen RC, Stevens JC, Ganguli M, Tangalos EG, Cummings JL, DeKosky ST. Practice parameter: early detection of dementia: mild cognitive impairment (an evidence-based review). Report of the Quality Standards Subcommittee of the American Academy of Neurology. 2001;56:1133-42.

50. Chui H, Zhang Q. Evaluation of dementia: a systematic study of the usefulness of the American Academy of Neurology's practice parameters. Neurology 1997;49:925-35.

51. Massoud F, Devi G, Moroney JT, et al. The role of routine laboratory studies and neuroimaging in the diagnosis of dementia: a clinicopathological study. J Am Geriatr Soc 2000;48:1204-10.

52. Knopman DS, DeKosky ST, Cummings JL, et al. Practice parameter: diagnosis of dementia (an evidence-based review). Report of the Quality Stan- 
dards Subcommittee of the American Academy of Neurology. Neurology 2001;56:1143-53.

53. Beck FK, Rosenthal TC. Prealbumin: a marker for nutritional evaluation. Am Fam Physician 2002;65: 1575-8.

54. Tuppo EE, Forman LJ, Spur BW, Chan-Ting RE, Chopra A, Cavalieri TA. Sign of lipid peroxidation as measured in the urine of patients with probable Alzheimer's disease. Brain Res Bull 2001;54:565-8.

55. Myagkova MA, Gavrilova SI, Lermontova NN, et al. Autoantibodies to beta-amyloid and neurotransmitters in patients with Alzheimer's disease and senile dementia of the Alzheimer type. Bull Exp Biol Med 2001;131:127-9.

56. Du Y, Dodel R, Hampel H, et al. Reduced levels of amyloid beta-peptide antibody in Alzheimer disease. Neurology 2001;57:801-5.

57. Yamada T, Tsujioka Y, Taguchi J, et al. Melanotransferrin is produced by senile plaque-associated reactive microglia in Alzheimer's disease. Brain Res 1999;845:1-5.

58. Sjogren M, Blomberg M, Jonsson M, et al. Neurofilament protein in cerebrospinal fluid: a marker of white matter changes. J Neurosci Res 2001;66: 510-6.

59. Silverberg GD, Heit G, Huhn S, et al. The cerebrospinal fluid production rate is reduced in dementia of the Alzheimer's type. Neurology 2001;57:1763-6.

60. Jack CR Jr, Petersen RC, Xu YC, et al. Prediction of $\mathrm{AD}$ with MRI-based hippocampal volume in mild cognitive impairment. Neurology 1999;52: 1397-403.

61. Dickerson BC, Goncharova I, Sullivan MP, et al. MRI-derived entorhinal and hippocampal atrophy in incipient and very mild Alzheimer's disease. Neurobiol Aging 2001;22:747-54.

62. Camicioli R, Moore MM, Sexton G, Howieson DB, Kaye JA. Age-related brain changes associated with motor function in healthy older people. J Am Geriatr Soc 1999;47:330-4.

63. Sencakova D, Graff-Radford NR, Willis FB, et al. Hippocampal atrophy correlates with clinical features of Alzheimer disease in African Americans. Arch Neurol 2001;58:1593-7.

64. Kaye JA, Swihart T, Howieson D, et al. Volume loss of the hippocampus and temporal lobe in healthy elderly persons destined to develop dementia. Neurology 1997;48:1297-304.

65. Chan D, Fox NC, Jenkins R, Scahill RI, Crum WR, Rossor MN. Rates of global and regional cerebral atrophy in $\mathrm{AD}$ and frontotemporal dementia. Neurology 2001;57:1756-63.

66. Mueller EA, Moore MM, Kerr DC, et al. Brain volume preserved in healthy elderly through the eleventh decade. Neurology 1998;51:1555-62.

67. Shoghi-Jadid K, Small GW, Agdeppa ED, et al. Localization of neurofibrillary tangles and betaamyloid plaques in the brains of living patients with Alzheimer disease. Am J Geriatr Psychiatry 2002;10:24-35.

68. Silverman DH, Small GW, Chang CY, et al. Positron emission tomography in evaluation of dementia: regional brain metabolism and long-term outcome. JAMA 2001;286:2120-7.

69. Olafsdottir M, Foldevi M, Marcusson J. Dementia in primary care: why the low detection rate? Scand J Prim Health Care 2001;19:194-8.

70. Doody RS, Stevens JC, Beck C, et al. Practice parameter: management of dementia (an evidencebased review). Report of the Quality Standards Subcommittee of the American Academy of Neurology. Neurology 2001;56:1154-66.

71. Peters R. The prevention of dementia. J Cardiovasc Risk 2001;8:253-6.

72. Stern Y, Moeller JR, Anderson KE, et al. Different brain networks mediate task performance in normal aging and AD: defining compensation. Neurology 2000;5 5:1291-7.

73. Mayeux R, Sano M. Treatment of Alzheimer's disease. N Engl J Med 1999;341:1670-9.

74. O'Brien JT, Ballard CG. Drugs for Alzheimer's disease. BMJ 2001;323:123-4.

75. Irizarry MC, Hyman BT. Alzheimer disease therapeutics. J Neuropathol Exp Neurol 2001;60:923-8.

76. Dominguez DI, De Strooper B, Annaert W. Secretases as therapeutic targets for the treatment of Alzheimer's disease. Amyloid 2001;8:124-42.

77. Schenk D, Barbour R, Dunn W, et al. Immunization with amyloid-beta attenuates Alzheimer-disease-like pathology in the PDAPP mouse. Nature 1999;400: 173-7.

78. Younkin SG. Amyloid beta vaccination: reduced plaques and improved cognition. Nat Med 2001;7: $18-9$.

79. Weiner HL, Lemere CA, Maron R, et al. Nasal administration of amyloid-beta peptide decreases cerebral amyloid burden in a mouse model of Alzheimer's disease. Ann Neurol 2000;48:567-79.

80. Sano M, Ernesto C, Thomas RG, et al. A controlled trial of selegiline, alpha-tocopherol, or both as treatment for Alzheimer's disease. The Alzheimer's Disease Cooperative Study. N Engl J Med 1997;336: 1216-22.

81. Brodaty H, Ames D, Boundy KL, et al. Pharmacological treatment of cognitive deficits in Alzheimer's disease. Med J Aust 2001;175:324-9.

82. Morris MC, Beckett LA, Scherr PA, et al. Vitamin E and vitamin $\mathrm{C}$ supplement use and risk of incident Alzheimer disease. Alzheimer Dis Assoc Disord 1998;12:121-6.

83. Fioravanti M, Flicker L. Efficacy of nicergoline in dementia and other age associated forms of cognitive impairment. Cochrane Database Syst Rev 2001;(4): CD003159.

84. Ditkoff EC, Crary WG, Cristo M, Lobo RA. Estro- 
gen improves psychological function in asymptomatic postmenopausal women. Obstet Gynecol 1991; 78:991-5.

85. Mulnard RA, Cotman CW, Kawas C, et al. Estrogen replacement therapy for treatment of mild to moderate Alzheimer disease: a randomized controlled trial. Alzheimer's Disease Cooperative Study [published erratum appears in JAMA 2000;284:2597]. JAMA 2000;283:1007-15.

86. Shumaker SA, Legault C, Thai L, et al. Estrogen plus progestin and the incidence of dementia and mild cognitive impairment in postmenopausal women: the Women's Health Initiative Memory Study: a randomized controlled trial. JAMA 2003; 289:2651-62.

87. LeBlanc ES, Janowsky J, Chan BK, Nelson HD. Hormone replacement therapy and cognition: systematic review and meta-analysis. JAMA 2001;285: 1489-99.

88. Zandi PP, Carlson MC, Plassman BL, et al. Hormone replacement therapy and incidence of Alzheimer disease in older women: the Cache County Study. JAMA 2002;288:2123-9.
89. Stewart WF, Kawas C, Corrada M, Metter EJ. Risk of Alzheimer's disease and duration of NSAID use. Neurology 1997;48:626-32.

90. Zandi PP, Breitner JC, Anthony JC. Is pharmacological prevention of Alzheimer's a realistic goal? Exp Opin Pharmacother 2002;3:365-80.

91. Moroney JT, Tang MX, Berglund L, et al. Lowdensity lipoprotein cholesterol and the risk of dementia with stroke. JAMA 1999;282:254-60.

92. Wolozin B, Kellman W, Ruosseau P, Celesia GG, Siegel G. Decreased prevalence of Alzheimer disease associated with 3-hydroxy-3-methyglutaryl coenzyme A reductase inhibitors. Arch Neurol 2000;57: $1439-43$

93. Yaffe K, Barrett-Connor E, Lin F, Grady D. Serum lipoprotein levels, statin use, and cognitive function in older women. Arch Neurol 2002;59:378-84.

94. Scott HD, Laake K. Statins for the prevention of Alzheimer's disease. Cochrane Database Syst Rev 2001;(4):CD003160.

95. Wiebe S, Nicolle MW. Recent developments in neurology [published erratum appears in BMJ 2002; 325:366]. BMJ 2002;324:656-60. 